\title{
Solar Driven Photocatalysis - an Efficient Method for Removal of Pesticides from Water and Wastewater
}

\author{
Rajandeep Kaur ${ }^{1}$, Harpreet Kaur ${ }^{2}$ (D) \\ 1 Louis Riel School, Division Winnipeg, Manitoba, Canada; myrajan786@gmail.com (R.K); \\ 2 Department of Chemistry, Lovely Professional University, Phagwara, Punjab, India; harpreet2.kaur@ 1pu.co.in (H.K); \\ * Correspondence: harpreet2.kaur@1pu.co.in;
}

Received: 1.07.2020; Revised: 26.08.2020; Accepted: 27.08.2020; Published: 1.09.2020

\begin{abstract}
Owing to extensive agricultural activity, the growth of the agrochemical sector has expanded substantially over the last several decades. The use of pesticides has raised significantly for recent years as farming practices have become very demanding. Pollution of water bodies has become widespread and detracting due to the accumulation of pesticides. The standard biological treatment based on microorganism action is not a suitable technique in the processing of pesticides present in water due to their contamination even at extremely low levels. Scientists have adopted various measures to decontaminate water and introduced other methods for pesticide abatement. The efficient and fruitful methodology of photocatalytic degradation is because of the advantage of its total mineralization and not its delegate transformation. So as to utilize practical, protected, and green science innovation, photocatalytic debasement of pesticides as an imaginative technique for future examinations, comprehension of the middle of the road arrangement, corruption pathway, biodegradability, and natural maintainability is required. The aim of the review is to present several technologies based on the solar-driven photocatalytic removal of pesticides from different waters.
\end{abstract}

Keywords: Wastewater treatment; pesticide degradation; photocatalytic degradation of pesticides; cost-effective water purification; green method of pesticide degradation.

Abbreviations: AOP-Advanced Oxidation Process; $\triangle \mathrm{E}-\mathrm{Band}$ Gap Energy; VB-Valence Band; CBConduction Band; $\mathrm{e}^{-}$-Electron; $\mathrm{h}^{+}$-Hole; UV/VIS/IR-Ultraviolet/ Visible/Infra-Red; DMSO-Dimethyl Sulphoxide; PZC-Point of Zero Charge; LC-Liquid Chromatography; GC-Gas Chromatography; MSMass Chromatography; TOF-Time of Flight; TOC-Total Organic Carbon; DOC-Dissolved Organic carbon; DT-Disappearance Time; IBR-Immobilized Biomass Reactor.

(C) 2020 by the authors. This article is an open-access article distributed under the terms and conditions of the Creative Commons Attribution (CC BY) license (https://creativecommons.org/licenses/by/4.0/).

\section{Introduction}

The agrochemical industry has significantly increased over the past few years due to extensive agricultural exercises [1]. Pesticides are the chemical substances that normally secure the agricultural commodities by controlling the broad array of pests and insects [2]. Numerous types of pesticides generate pollution of air, soil, groundwater, and surface water, and detrimental to human well being as they are discharged into the atmosphere because of runoff from farming and civic areas $[3,4]$. Pesticides are the second biggest potable water contaminant and pose the greatest threat $[5,6]$. A pesticide should be harmful to the intended pests but not to non-intended species like human beings and many other creatures. However, due to the absence of precision, it is poisonous to both intended and non-intended species. The biggest 
reason for humans, fishes, birds, and bee's infection was the non - specific pesticide toxicity [7].

The treatment of these substances from soil and water sources by effective and ecofriendly methods is the need of an hour because of the significant implications of pesticides on humans and the environment. It can also be awfully expensive and difficult to clean up these pollutants. Many of these contaminants need high treatment preferences and innovative degradation technologies [8]. Wastewater-containing pesticides are not very commonly treated using biological approaches because they are harmful to microorganisms, and thus their biodegradation is unattainable [9]. The need for alternative wastewater treatment systems is, therefore, gradually becoming a prime concern for federal agencies, regulatory authorities, and the public in general. In view of this, it is essential to advance comprehensive methods that advocate the degradation of such bio-recalcitrant organic substances [10].

Numerous methods of treatment for the elimination of pesticide contaminants from groundwater and surface waters are accessible. Among these advanced oxidation processes (AOP), particularly photooxidation, appears to be especially efficient at low pesticide concentration. Thus, in developing countries, where a large percentage of the population has a reduced approach to enhanced drinking water, the arrangement for effective treatment processes for sewage/wastewater and drinking water is the key issue [11].

The present review focuses on a method designed to help address this type of nonbiodegradable hazardous substance treatment problem. Advanced oxidation processes (AOPs) that quickly become the most commonly used water treatment technologies for organic contaminants, such as pesticides that can not be treated by traditional techniques due to their high chemical stability and low biodegradability. [12-14].

\section{Review}

\subsection{Solar photocatalytic degradation.}

\subsubsection{Photocatalysis.}

Photocatalysis is defined as the "acceleration of a photoreaction by the action of a catalyst" [15]. The overall mechanism of photocatalysis is considerably basic, a photon of light produces a charge- carrier pair with energy equal to or more than the bandgap energy. Because of this change in energy, the formation of electron and holes takes place to produce hydroxide and other radicals for the break-down of organic pollutants. [16]. The photocatalytic activity of the catalyst depends on the ability to generate electron-hole pairs, which further produce free radicals (e.g., hydroxyl radicals: $\bullet \mathrm{OH})$.

In contrast to other advanced oxidation methods, which use oxidants such as hydrogen peroxide $\left(\mathrm{H}_{2} \mathrm{O}_{2}\right)$ and ozone $\left(\mathrm{O}_{3}\right)$, the advantage of this method is that costly oxidizing agents are not requisite as atmospheric oxygen is the oxidant $[17,57,58]$.

\subsubsection{Advantage of photocatalysis.}

(i) Nearly all organic and inorganic contaminants can be successfully degraded and mineralized by photocatalysis.

(ii) The end products of photocatalysis are eco-friendly compounds such as $\mathrm{H}_{2} \mathrm{O}$ and $\mathrm{CO}_{2}$, simpler salts, and minerals. Thus, photocatalysis is considered as green technology.

(iii) No other oxidant is required for the process as atmospheric oxygen is used as an oxidant. 
(iv)The photocatalysts are non- toxic, cost-effective, extremely sustainable, chemical, and biologically inert, immiscible, renewable, and reusable in most conditions.

(v) Photocatalyst activation takes place in the presence of sunlight as well as artificial light.

(vi) Photocatalysis is also compared to the activated carbon adsorption method for large scale operations [18].

\subsection{Advanced oxidation processes.}

Advanced oxidation processes (AOPs) [19] is a class of oxidation methods that are developed on the basis of the in situ production of immensely reactive and oxidizing species (hydroxyl ions), combine with the organic pollutant molecules and give rise to the steady degradation of pollutants [20]. In the last decade, the photochemical AOPs have developed considerable concern, which prompted the use of renewable energy sources as a means of promoting chemical methods. Solar radiation was established as the possible source for photochemical AOPs, especially for water detoxification and disinfection with attractive potential for real applications [21]. Homogeneous and heterogeneous photocatalysis is the most widely studied technologies for water disinfection using solar radiation. Both detoxification and water disinfection processes have been intensively studied in laboratory, bench, and pilot plant scales. [22].

Although AOPs use varying reagent processes, however, all procedures in common not only highly selective but highly reactive radical species which target most organic molecules via the general scheme described by Equation (1):

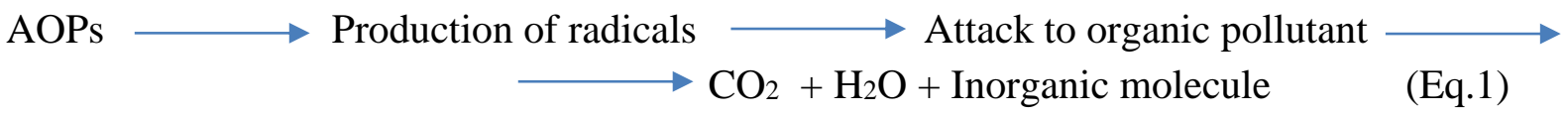

\subsubsection{Heterogeneous photocatalysis.}

Among the AOPs, heterogenous photocatalysis using semiconductor catalysts has demonstrated its effectiveness in degrading a wide range of harmful pollutants into biodegradable compounds and gradually mineralizing them to water and carbon dioxide [23]. The term heterogeneous refers to dual-phase, i.e., the catalyst in the solid phase while the contaminants in the aqueous phase (2). Two or more phases are used along with the light source (UV/Solar radiation) in the presence of a semiconductor catalyst $\left(\mathrm{TiO}_{2}, \mathrm{ZnO}, \mathrm{ZnS}, \mathrm{CdS}\right.$, etc.) in the heterogeneous process.

Holes and electrons generated by the AOPs give rise to a redox reaction for the degradation of contaminants [24]. The semiconductor assisted photocatalysis is comprehensively studied AOPs, due to its ability to degrade many recalcitrant chemicals in gaseous and aqueous environments [25]. Nano based semiconductors are the widely used heterogeneous catalysts [26]. Due to its distinctive photophysical and photocatalytic properties such as bandgap energies charge transport characteristics, electronic structures, the life of excitation state, and light absorption properties, the interest in these semiconductor particles arises [27]. Among the various types of nanomaterials, semiconducting nanoparticles have been widely studied due to their wide applications in electronic devices [28], solar cells [30], and photocatalysis [29].

The interest in using semiconductors as photocatalysts arises because they are:

(i) Economical

(ii) Harmless 
(iii) Have a large surface area to volume ratio

(iv) Have broad absorption spectra with high absorption coefficients

(v) Displays size-tunable properties (can be modified by doping, size reduction, and sensitizers)

(vi) Allowing facility for the multi-electron transfer process

(vii) Capable of enhanced use without substantial loss of photocatalytic activity [31].

\subsubsection{Principle of the heterogenous photocatalytic oxidation process.}

Organic pollutants are decimated during the photocatalytic oxidation process by an energetic light source and an oxidizing agent such as oxygen or air in the presence of photocatalyst semiconductors (e.g., $\left.\mathrm{TiO}_{2}, \mathrm{ZnO}\right)$ [32].

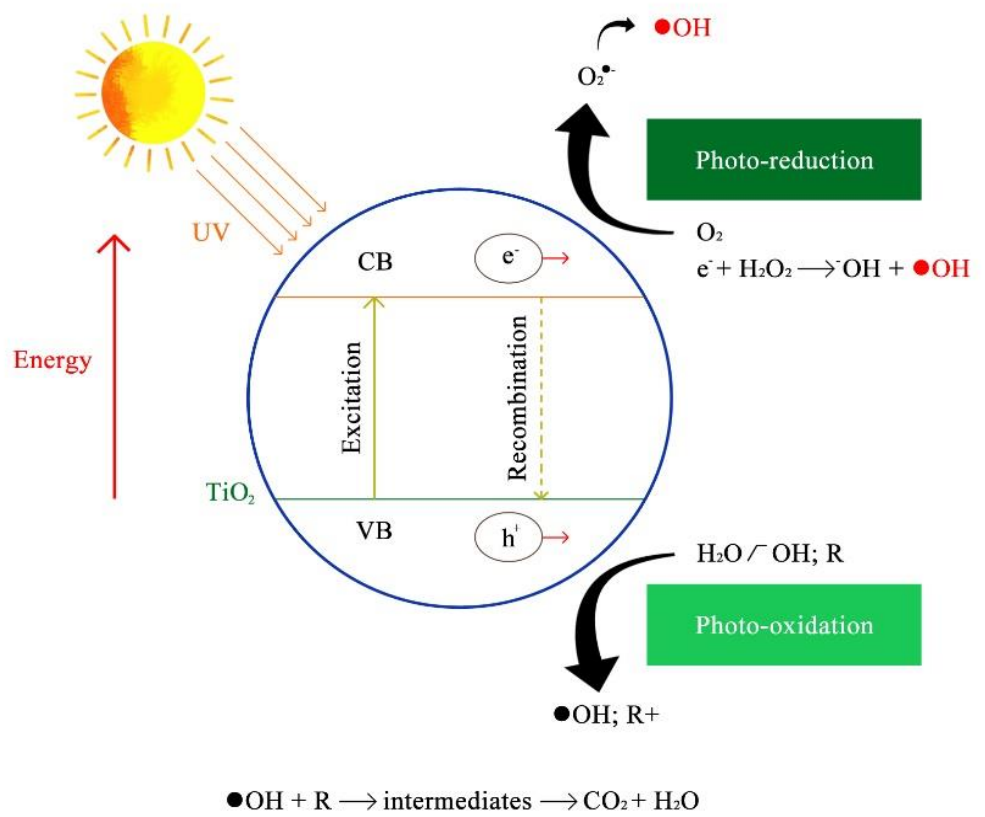

Figure 1. Schematic diagram demonstrating the principle of photocatalysis.

As shown in Fig.1, the photons with energy more than the bandgap energy $(\Delta \mathrm{E})$ give rise to valence band (VB) electrons excitation, which then induces the potential reaction with organic contaminants. Usually, the absorption of photons with energy less than $\Delta \mathrm{E}$ or longer wavelengths induces energy dissipation in the form of heat. The irradiation of the surface of photocatalyst with adequate energy gives rise to the production of a positive hole $\mathrm{h}^{+}$and an electron $\left(\mathrm{e}^{-}\right)$in the valence and conduction band, respectively. The electron in the conduction band reduces the oxygen adsorbed on the photocatalyst $\left(\mathrm{TiO}_{2}\right)$, whereas the positive hole oxidizes the pollutant directly or water to form hydroxyl radicle.

The activation of $\mathrm{TiO}_{2}$ by UV light can be shown as:

$\mathrm{TiO}_{2}+h v(\lambda<387 \mathrm{~nm}) \longrightarrow \mathrm{e}^{-}+\mathrm{h}^{+} \quad$ (Eq.2)

$\mathrm{e}^{-}+\mathrm{O}_{2} \longrightarrow \mathrm{O}_{2}^{-} \quad$ (Eq.3)

The oxidative and reductive steps can be expressed as:

Oxidation Reaction:

$\mathrm{h}^{+}+$Organic $(\mathrm{R}) \longrightarrow$ Intermediates $\longrightarrow \mathrm{CO}_{2}+\mathrm{H}_{2} \mathrm{O} \quad$ (Eq.4)

$\mathrm{h}^{+}+\mathrm{CO}_{2}+\mathrm{H}_{2} \mathrm{O} \longrightarrow \mathrm{OH}+\mathrm{H}^{+} \quad$ (Eq.5)

Reduction Reaction:

$\mathrm{OH}+$ Organic $(\mathrm{R}) \longrightarrow$ Intermediates $\longrightarrow \mathrm{CO}_{2}+\mathrm{H}_{2} \mathrm{O}$ (Eq.6) 
The photocatalytic oxidation process shows a hydroxyl radical generation in the above steps. In the break-down of organic contaminants, oxygen stops the coupling of a hole and the hydroxyl radical. These hydroxyls are generated by the oxidation of adsorbed water (primary oxidant). The $\mathrm{OH}^{-}$targets organic compounds such as aniline, nitrophenols, and chlorinated aromatics that lead to different reaction intermediates from different compounds. The final degradation products $\mathrm{H}_{2} \mathrm{O}$ and $\mathrm{CO}_{2}$, are produced by the consequent reaction of intermediate with $\mathrm{OH}^{-}$.

It has been observed that in the photocatalysis of various carbon-based pollutants, there is an accumulation of electrons in the conduction band (CB), when the reduction of oxygen and the oxidation process do not occur simultaneously. This results in an increase in the rate of reaction between an electron and a positive hole. It is, therefore, essential to avoid electron accumulation for effective photocatalytic oxidation. $\mathrm{TiO}_{2}$ is the most extensively researched system in photocatalysis because of its low cost and availability, desirable physical and chemical properties, and high activity. Anatase and rutile forms, among three common $\mathrm{TiO}_{2}$ crystalline forms, were extensively examined as photocatalysts.

As a photocatalyst, anatase has been proved to be more efficient than rutile. The $\mathrm{ZnO}$ photocatalyst also follows the oxidation pathways like $\mathrm{TiO}_{2}$, such as the direct oxidation by photo-generated holes and generation of $\mathrm{OH}$.

In concentrated sunlight, $\mathrm{ZnO}$ was stated to be as reactive as $\mathrm{TiO}_{2}$, since the bandwidth of $\mathrm{ZnO}$ is similar to $\mathrm{TiO}_{2}$. Other metal oxides have also been investigated, such as $\mathrm{CeO}_{2}, \mathrm{SnO}_{2}, \mathrm{WO}_{3}, \mathrm{CdS}$, for degradation of organic pollutants. The rate of photocatalysis of organic compounds can be shown by a pseudo-first-order manner, at low substrate concentration with the following equation:

$$
\ln \mathrm{C} / \mathrm{C}_{0}=\text { kobs.t } \quad \ldots \text { (Eq.7) }
$$

where,

kobs - the apparent reaction rate constant,

$\mathrm{t}$ - reaction time,

$\mathrm{C}_{0}$ - initial concentration,

$\mathrm{C}$ - residual concentration of a pollutant at time $\mathrm{t}$.

For the degradation of different pesticides and herbicides present in stormwater and wastewater effluent, varying light sources like UV lamps and solar radiation have been used.

\subsection{Modification of photocatalysts.}

The semiconductors are effective for organic pollutants degradation but with some disadvantages, which include photo-corrosion, recombination of photoexcited species, and poor activity in the visible light [31]. To address these concerns, surface modification of photocatalyst is important to improve the photosensitivity. The semiconductor surfaces are modified by the addition of metals, doping, pairing with other semiconductors are advantageous in accelerating the electron-holes recombination rate and thus improves the quantum yield of the photocatalytic process. The modification of photocatalyst by doping is the most favorable approach in which the addition of other metal oxide tailored the bandgap and lead to substantial transformations in the natural structure of the material. 


\subsubsection{Doping.}

Doping typically includes the use of metals or non-metals and is intended to raise the photocatalytic activity of a semiconductor by reducing the energy of excitation. The doping of semiconductors is the process of locally manipulating their charge-carrier density and conductivity [33]. It is the inclusion of 'foreign elements' into the parent photocatalyst, with the purpose of improving the net separation of photo-generated charges, without giving rise to new crystalline forms. New energy levels between the valence and conduction band of the catalyst are created by the doping of photocatalyst, which in turn decreases its bandgap. Metallic doping attracts electrons from the conduction band and decreases the reaction of the recombination of charges. When the dopant material has an energy level below the CB or above the VB, a material is doped to expand the life of charge carriers. This acts as a charge trapping center resulting in the expansion of wavelength towards the visible region of the spectrum.

Benefits of doping (2):

The following are the few advantages of doping nanomaterials:

(i) Increase the overall efficiency of the catalyst.

(ii) Doping includes the implementation of new energy levels into the bandgap.

(iii) Expanded electron trapping because of greater defect sites leads to improve the photocatalytic ability.

(iv) It forms quasi-stable energy states within the bandgap, giving rise to surface defects that alter the electronic and optical properties.

(v) Improvements to semiconductor surfaces are favorable in reducing the electron and holes recombination rate.

\subsubsection{Photo fenton $\left(\mathrm{H}_{2} \mathrm{O}_{2} / \mathrm{Fe}^{2+} / \mathrm{UV}\right)$.}

According to Zepp et al. (1992), the classical Fenton reaction [34] could be photocatalyzed using UV radiations to stimulate the catalytic reduction, in $\mathrm{H}_{2} \mathrm{O}_{2}$ aqueous solutions, of $\mathrm{Fe}^{3+}$ into $\mathrm{Fe}^{2+}$, which enhance the production of $\mathrm{OH}$ radicals, by the following reaction [20]:

$$
\mathrm{Fe}^{3+}+\mathrm{H}_{2} \mathrm{O}+\mathrm{hv} \longrightarrow \mathrm{Fe}^{2+}+\mathrm{H}^{+}+\mathrm{OH} \quad \text { (Eq.8) }
$$

At $\mathrm{pH}$ 2.8-3.5, $[\mathrm{Fe}(\mathrm{OH})]^{2+}$ ion is the pre-eminent form of $\mathrm{Fe}^{3+}$, which plays a major role in the photo-Fenton process [35]. In the photo-Fenton reactions, the production of $\bullet \mathrm{OH}$ radicals has been quantified in aqueous solutions comprising of complexes of $\mathrm{Fe}$ (III)-oxalate and hydrogen peroxide [34]. Moreover, UV irradiation also has the capability to directly decompose $\mathrm{H}_{2} \mathrm{O}_{2}$ molecules into hydroxyl radicals in the photo-Fenton process. Various UV regions as a light energy source, like UVA $(\lambda=315-400 \mathrm{~nm})$, UVB $(\lambda=285-315 \mathrm{~nm})$, and $\mathrm{UVC}(\lambda<285 \mathrm{~nm})$ can be used in the photo-Fenton process. It is worth noting that UV radiation has an important impact on the degradation rate of organic contaminants due to its intensity and wavelength. The substantial cost-effective use of artificial light is still a downside to this method.

However, a recently developed, alternative approach known as the solar photo-Fenton process uses sunlight (at wavelengths $\lambda>300 \mathrm{~nm}$ ) based on solar collectors for photocatalytic remediation and disinfection of waters [36,37]. As indicated by the application of the recently known, easy-to-use environmental-economic index, this solar photo-Fenton process is perhaps a far better system than the traditional light-driven photo-Fenton method, both from the economic and environmental standpoints. The behavior of photons in the photo- 
Fenton process is complicated. In classical Fenton's reaction, in which hydroxyl radicals are formed, it has the disadvantage of wide $\mathrm{Fe}^{3+}$ accumulation, thus reducing the efficacy of treatment. This limitation is prevented in the latter process, since reductive photolysis of $[\mathrm{Fe}(\mathrm{OH})]^{2+}$, has the benefit of regenerating the $\mathrm{Fe}^{2+}$ ions that catalyze Fenton's reaction and yielding additional $\mathrm{OH}$ radicals $[38,39]$. Quantum efficiency of reaction was found out to be $0.04 \pm 0.04$ at $313 \mathrm{~nm}$ and $0.017 \pm 0.003$ at $360 \mathrm{~nm}(293 \mathrm{~K}$, ionic strength $=0.03 \mathrm{M})$ [39]. A novel kinetic method was recently developed for finding out the quantum yields of photolysis of Iron (III) complexes like $[\mathrm{Fe}(\mathrm{OH})]^{2+}$, it used (DMSO) as a $\bullet \mathrm{OH}$ probe compound [40]. It was observed that each quantum yield values declined with an increase in wavelength (240 $380 \mathrm{~nm}$ ) for the photolysis reaction of the monomeric Fe(III) complexes. [40]. This photoFenton process has also been universally used for the treatment and purification of polluted waters and landfill leachates [41].

As compared to heterogeneous photocatalysis with $\mathrm{TiO}_{2}$, the great benefit of the photoFenton process is its sensibility to light up to $600(580) \mathrm{nm}$. The photo-Fenton process allows quite effective use of sunlight. The drawback of the photo-Fenton process involves aggressive treatment due to the low $\mathrm{pH}$ required (usually below 4) and high consumption of $\mathrm{H}_{2} \mathrm{O}_{2}$ [42].

\subsection{Types of reactors used for photocatalysis.}

The majority of the wastewater photocatalytic treatment processes are usually conducted in the suspension. The source is catalyst suspended in the form of fine particles in the least concentration in polluted water [43]. The state of photocatalyst, i.e., suspension or immobilization normally classifies the photocatalytic reactors [44]. The most frequently used reactors include a fluidized bed, sequence, fixed-bed, single-phase reactor, an immobilized membrane reactor, a reactive wall reactor, and a photocatalytic membrane reactor [45]. Photocatalytic reactors either use solar or artificial UV light, and in total pollutant degradation, the intensity of light (UV/VIS/IR/Solar) radiation plays a significant role, but large-scale industrial reactors are based primarily on solar light [46]. The reactor shall be constructed so that it can provide the stationary photocatalyst with a high surface area to expose the maximum of its area to the light. The larger available surface area for the photocatalyst will improve the mass transfer rate and increase the adsorption rate for the improvement of photocatalytic activity. For the photocatalytic reaction, the reactor also should absorb minimum energy. For now, various types of reactors are invented to enhance the efficacy of the system by altering the reactor configuration, such as shape and dimensions, surface immobilization of the photocatalyst, etc. The modification aims to maximize the contact area so that mass transfer and quantum yield can be increased to ensure optimal photocatalytic performance. Thus, the overall catalytic efficiency of the photocatalytic system is strongly dependant on the type of photoreactor [2, 59].

\subsection{Plant design.}

A photocatalytic plant can be used for either $\mathrm{TiO}_{2}$ or photo-Fenton. The surface area of the solar collector depends primarily on the wastewater to be treated and on the irradiation conditions of the plant. In either case, it is necessary to separate the catalyst $\left(\mathrm{TiO}_{2}\right.$ or $\mathrm{Fe}$ ) and reuse it very often. The acid or base is added to reach the isoelectric point (point of zero charges, $\mathrm{PZC}$ ) of the suspension, where the treated water containing $\mathrm{TiO}_{2}$ is stored in the tank. The PZC point is mainly around $\mathrm{pH}$ 7. It takes only a few hours for the whole catalyst to 
descend to the bottom of the tank, depending on the size of the tank and concentration of the catalyst. The treated clean water can be discharged through a microfiltration membrane to remove any slight catalyst residue remaining. The catalyst recovered from the base of the tank can be reused under these conditions. It is impossible to prolong this recycling limitlessly. However, it has been shown that over ten cycles can be achieved without any efficiency reduction. The number of cycles depends primarily on the contaminated water being treated. The concentration of contaminants, the salt content of the water, and type of heteroatoms produced during their mineralization, desired quality of the treated water, etc. are also causally related to catalyst recycling [47].

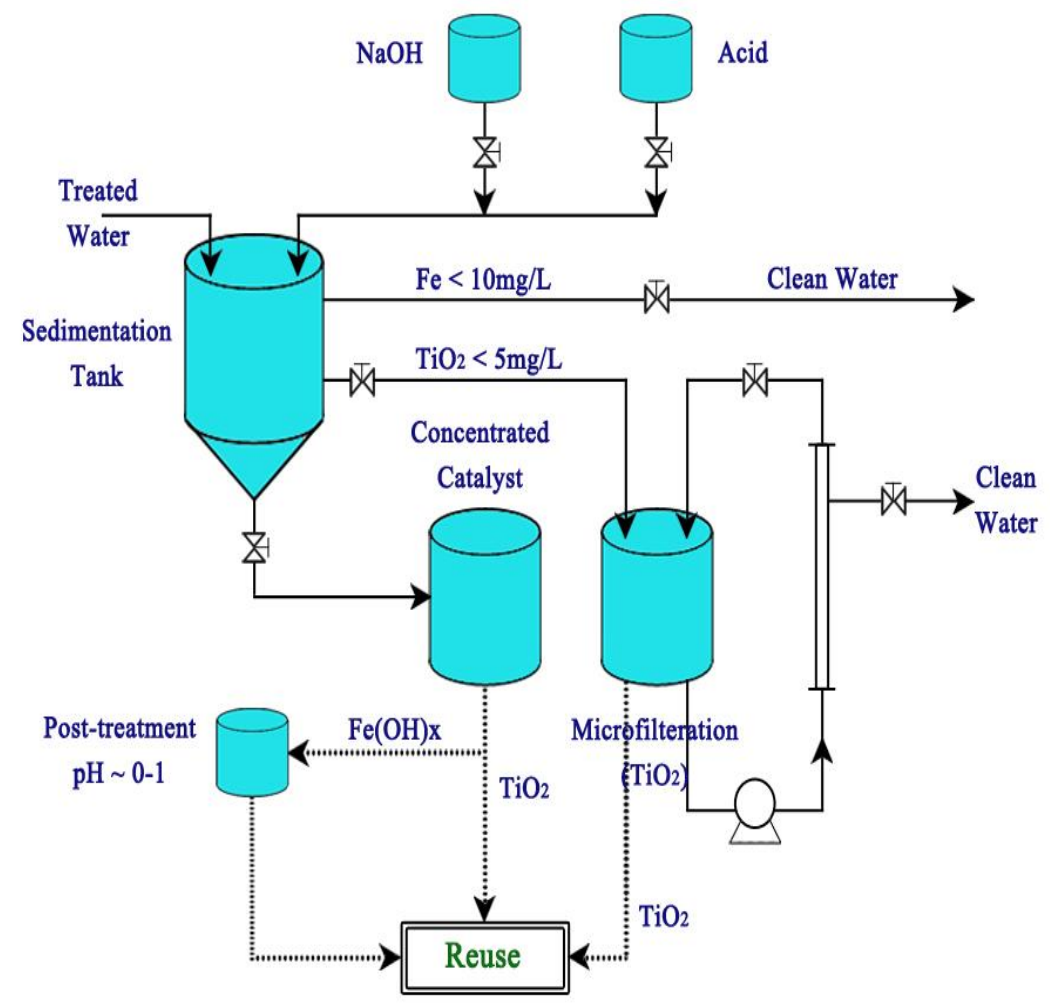

Figure 2. Photocatalytic recycling.

Iron separation is a different process. The $\mathrm{pH}$ of the treated water must be adjusted to attain iron hydroxide precipitation. The supernatant water can be discharged directly, and the precipitate can be reused, if necessary. The iron hydroxide can then be dissolved at very acid $\mathrm{pH}(0-1)$, and this very acid concentrated iron solution can be used to obtain the correct "photoFenton $\mathrm{pH}$ conditions" $(2.5<\mathrm{pH}<3.0)$, by adding it to untreated wastewater. It may not be necessary to remove the iron from the treated water because often extremely low iron concentrations are sufficient.

\subsection{Degradation of pesticides.}

The transformation of parent compounds in water to prevent their toxicity is a desirable feature in the photodegradation of pesticides. The main purpose is the mineralization of pesticides. $\mathrm{OH}$ is the central species involved in the oxidation of the organic substrate. But the free radical $\mathrm{HO}_{2}$ and its conjugate $\mathrm{O}_{2} \cdot-$ also plays an important role, although those radicals are much less reactive than $\mathrm{OH}$. All these free radicals react with pesticides by hydrogen abstraction or electrophilic addition to double bonds. Furthermore, the radicals react with $\mathrm{O}_{2}$ to give organic peroxyl radicals $\left(\mathrm{ROO}^{-}\right)$, initiating different oxidative reactions leading the total 
mineralization of the pesticides. Since $\mathrm{OH}$ is non-selective, numerous and different transformation products (intermediates) can be formed at low concentrations being in certain cases more persistent and toxic than the parent compounds.

Mineralization $\longrightarrow$ Organic pesticide $\longrightarrow \mathrm{CO}_{2}+\mathrm{H}_{2} \mathrm{O}+\mathrm{Cl}^{-}+\mathrm{NO}_{3}^{-}+\mathrm{SO}_{4}^{2-}+\mathrm{PO}_{4}{ }^{3-}$ etc. (Eq.9)

The chromatographic techniques like liquid chromatography (LC), Gas chromatography (GC) coupled to mass spectrometry (MS), and time-of-flight (TOF) detection systems are used for measuring the presence of pesticide residues in water. Since it is not possible to identify all the transformation products generated in photooxidation. The measure of total organic carbon and, more explicitly, dissolved organic carbon (DOC) is important in the process because the determination of $\mathrm{CO}_{2}$ must be stoichiometric with the organic carbon in the parent pesticide. This determination can be carried out in an easy and swift way to know the mass balance and the remaining number of metabolites [48].

Navarro et al. (2009) studied the photodegradation of eight pesticides (azoxystrobin, hexaconazole, kresoxim-methyl, tebuconazole, pyrimethanil, triadimenol, primicarb, propyzamide) in leaching water using the tandem $\mathrm{ZnO} / \mathrm{Na}_{2} \mathrm{~S}_{2} \mathrm{O}_{8}$ as photosensitizer/oxidant and compound parabolic collectors under natural light at pilot plant scale. The disappearance of the pesticides followed first-order kinetics following the Langmuir curve, and complete disintegration occurred within $120 \mathrm{~min}$. The disappearance time (DT75), referred to as the normalized illumination time ( $\mathrm{t} 30 \mathrm{~W})$, was less than $3 \mathrm{~min}$ in each case [49]. The efficiency of solar heterogeneous $\mathrm{TiO}_{2}$ photocatalysis and homogeneous photo-Fenton reaction for removal of Lambda Cyhalothrin, Chlorpyrifos, and Diazinon from the pesticide wastewater industry was investigated by Alalm et al. (2015). The combined processes resulted in the complete removal of pesticide fractions, i.e., $100 \%$ for Diazinon, $97 \%$ for Lambda Cyhalothrin, and $91 \%$ for Chlorpyrifos. The experimental data were analyzed by the Freundlich and the Langmuir isotherm. Pseudo first order and pseudo-second-order kinetic models were tested for the experimental results [50].

Hincapie et al. (2005) studied the degradation of different pesticides on a pilot plant scale using photo-Fenton and $\mathrm{TiO}_{2}$ photocatalysis driven by solar energy. Two different iron concentrations have been tested using TOC mineralization. Vibrio fischeri (Microtox1) toxicity assays were used for the study. Almost complete mineralization and total detoxification were obtained. It was determined that the detection of chloride could be an important parameter for predicting the toxicity of chlorinated compounds [9]. The photocatalysis of four pesticides (methomyl, diuron, formetanate, and imidacloprid) was studied by Malato et al. (2003), at a pilot scale in two systems: two-phase catalysis with titanium dioxide and one-phase catalysis by photo-Fenton in the presence of natural-solar UV light. The total removal of the parent compounds occurred with $90 \%$ mineralization, and toxicity reduction below the threshold (EC50) was attained for all tested pesticides [47].

Solar driven heterogeneous photocatalytic processes have been extensively applied for pesticide degradation. According to Bandala (2014), triazinic pesticides have been successfully removed from water by using solar driven Fenton-like processes as well as phenol and phenolic derivatives, organophosphorus, chloroacetic acid, and dimethylurea pesticides [22]. Berberidou et al. 2016, studied an alternative method for the remediation of water containing pesticides and constructed wetlands. This integrated system based on solar photocatalysis and 
constructed wetlands has the potential to effectively detoxify wastewater containing pesticides, producing a purified effluent that could be exploited for reuse applications [10]. The photocatalytic degradation of three chloroacetanilides (propachlor, s-metolachlor, alachlor) and five s-triazines (simazine, prometryn, terbutryn, atrazine, and terbuthylazine) herbicides was investigated by Fenoll et al. (2012). At the pilot plant scale, zinc oxide and titanium dioxide were used as semiconductors under sunlight. The addition of $\mathrm{Na}_{2} \mathrm{~S}_{2} \mathrm{O}_{8}$ to the semiconductor suspensions enhanced the rate of photooxidation. $\mathrm{ZnO}$ was found to be most efficient amongst all the catalysts understudy for the removal of herbicides. The results revealed that $70 \%$ of the herbicide quantity was degraded after $4 \mathrm{hrs}$ of illumination in the selected system [51].

Moreira et al. (2012) demonstrated the treatment of pesticide-containing wastewater resulting from phytopharmaceutical plastic containers washing, combining a preliminary biological pre-treatment step, using an immobilized biomass reactor (IBR), with advanced oxidation processes (AOPs). Heterogeneous $\left(\mathrm{TiO}_{2} / \mathrm{UV}\right.$ and $\mathrm{TiO}_{2} / \mathrm{H}_{2} \mathrm{O}_{2} / \mathrm{UV}$, both with and without acidification) and homogeneous (UV, $\mathrm{H}_{2} \mathrm{O}_{2} / \mathrm{UV}, \mathrm{Fe}^{2+} / \mathrm{H}_{2} \mathrm{O}_{2} / \mathrm{UV}$, and $\mathrm{Fe}^{2+} / \mathrm{H}_{2} \mathrm{O}_{2}$ systems were tested using a solar pilot plant. The wastewater exhibited a moderate organic load, high biodegradability, and nineteen pesticides were quantified in the range of 0.02-45 $\mathrm{mg} \mathrm{L}^{-1}$, representing 14-19\% of total DOC [52]. A mixture of five pesticides Cymoxanil, Dimethoate, Oxamyl Methomyl, and Pyrimethanil, was completely mineralized in a combined solar photocatalytic-biological pilot plant by Malato et al. (2007). Two advanced oxidation processes (AOPs: $\mathrm{TiO}_{2}$ and photo-Fenton) were employed for enhancing the biodegradability of wastewater, and an immobilized biomass reactor (IBR) was used for the following continuous biological treatment. $\mathrm{TiO}_{2}$ photocatalysis experiments were carried out in a small (35 L) solar pilot plant made up of only three compound parabolic collectors (CPCs), whereas photo-Fenton tests were carried out in a much bigger $(75 \mathrm{~L})$ solar pilot plant with four CPCs units. The initial pesticide concentrations in the mixture were $50 \mathrm{mg} \mathrm{L}^{-1}$ each. The $\mathrm{TiO}_{2}$ catalyst concentration employed was $200 \mathrm{mg} \mathrm{L}^{-1}$, and two different $\mathrm{Fe}^{2+}$ concentrations, $20 \mathrm{mg} \mathrm{L}^{-1}$, and $55 \mathrm{mg} \mathrm{L}^{-1}$, were used in the photo-Fenton tests. Toxicity (Vibrio fischeri) and biodegradability assays (Zahn-Wellens test) were also performed to monitor toxicity and biodegradability of samples at different stages of photo-Fenton treatment. The complete removal of the pollutants with more than $90 \%$ mineralization and complete nitrification was achieved by the combined system [53].

$\mathrm{TiO}_{2}$ has been confirmed for its dominance in removing herbicides such as malathion, methamidophos, chlorfenapyr, phoxim, dichlofenthion, bromophos ethyl, bromophos methyl, atrazine, cyanazine, prometryne, propazine, chlorotoluron, metobromuron, isoproturon cinosulfuron, triasulfuron, pirimiphos-methyl, dichlorvos and phosphamidon, diquat, paraquat, triclopyr, parathion, and pentachlorophenol. However, it is necessary to further study the potential and convenient applications of $\mathrm{TiO}_{2}$, including oxidative degradation. The use of $\mathrm{TiO}_{2}$ photocatalysis is currently increasing as an oxidation process for water treatment [54].

Apart from that, $\mathrm{CuO}$ nanoparticles have been found to possess photocatalytic activity on few pollutant dyes [55]. Biosynthesized $\mathrm{ZnO}$ nanoparticles degraded Congo red, which is one of the carcinogenic textile dyes, has been photodegraded by $83.33 \%$ at a $\mathrm{pH}$ of 6.5 due to the as-synthesized zinc oxide nanostructures indicating its potential application for wastewater treatment [56].

According to the study done by Alista et al., [60] photo-Fenton and heterogeneous photocatalysis were found to be effective in reducing pesticide residues in water. The use of semiconductors like $\mathrm{ZnO}$ and $\mathrm{TiO}_{2}$ in conjugation with $\mathrm{Na}_{2} \mathrm{~S}_{2} \mathrm{O}_{8}$ (as an oxidant) was indeed 
very efficient in mineralization, and with $\mathrm{ZnO} / \mathrm{Na}_{2} \mathrm{~S}_{2} \mathrm{O}_{8}$ treatment, the conversion rate was about 1.3 times more than that under $\mathrm{TiO}_{2} / \mathrm{Na}_{2} \mathrm{~S}_{2} \mathrm{O}_{8}$ treatment.

Recent work has been carried out on the photocatalytic degradation of 2,4-dinitrophenol through the use of hybrid material composed of $\mathrm{Bi} / \mathrm{Bi}_{2} \mathrm{O}_{3} / \mathrm{C}$ [61]. The photooxidation rate of $\mathrm{Bi} / \mathrm{C}-2$ was shown to be 1.60-fold that of $\mathrm{Bi}_{2} \mathrm{O}_{3}$ and 2.47-fold that of $\mathrm{g}_{-} \mathrm{C}_{3} \mathrm{~N}_{4}$ in 2,4-DCP degradation. Hybrid catalysts are also extremely stable, and photocatalytic activity can be sustained over four successive cycles. Improved photocatalytic efficiency can be due to improved light absorption, accelerated transfer and separation of photo-generated carriers, and the SPR effect of metallic bi and conductive carbon support. The key active species in the photochemical reaction cycle of $\mathrm{Bi} / \mathrm{C}-2$ is known as oxidative holes, while hydroxyl and superoxide radicals can also play auxiliary roles during photodegradation.

Table 1. Photocatalytic degradation of some pesticides.

\begin{tabular}{|c|c|c|}
\hline S.No. & Pesticide & Photocatalysts \\
\hline 1. & Monocrotophos, Endosulfan, Chlorpyrifos & $\mathrm{TiO}_{2}$ coated on polymeric beads \\
\hline 2. & Chlorotoluron, Diuron, Fluometuron, Isoproturon, Linuron & $\mathrm{ZnO}, \mathrm{TiO}_{2}, \mathrm{WO}_{3}, \mathrm{SnO}_{2}, \mathrm{ZnS}$ \\
\hline 3. & Pyrimethanil & $\mathrm{TiO}_{2} \mathrm{P} 25$ \\
\hline 4. & Imidacloprid & $\mathrm{TiO}_{2}$ and $\mathrm{TiO}_{2}-$ Based hybrid \\
\hline 5. & Thiamethoxam, Imidacloprid, Acetamiprid & $\mathrm{ZnO} / \mathrm{Na}_{2} \mathrm{~S}_{2} \mathrm{O}_{8}, \mathrm{TiO}_{2} \mathrm{P} 25 / \mathrm{Na}_{2} \mathrm{~S}_{2} \mathrm{O}_{8}$ \\
\hline 6. & Cyprodinil, Fludioxonil & $\mathrm{ZnO}, \mathrm{TiO}_{2}$ \\
\hline 7. & Fenamiphos & $\mathrm{ZnO}, \mathrm{TiO}_{2}, \mathrm{WO}_{3}, \mathrm{SnO}_{2}$ \\
\hline 8. & Malathion & $\mathrm{WO}_{3} / \mathrm{TiO}_{2}$ \\
\hline 9. & Carbofuran & $\mathrm{ZnO}, \mathrm{TiO}_{2} \mathrm{P} 25$ Degussa \\
\hline 10. & $\begin{array}{l}\text { Simazine, Prometryn, Terbutryn, Atrazine, Terbutylazine, } \\
\text { Propachlor, Alachlor, S-metolachlor }\end{array}$ & $\mathrm{ZnO}, \mathrm{TiO}_{2}$ \\
\hline 11. & $\begin{array}{l}\text { Ethoprophos, Isoxaben, Metalaxyl, Metribuzin, } \\
\text { Pencycuron, Pendimethalin, Propanil, Tolclofos-methyl }\end{array}$ & $\mathrm{ZnO}, \mathrm{TiO}_{2}, \mathrm{WO}_{3}, \mathrm{SnO}_{2}, \mathrm{ZnS}$ \\
\hline 12. & Methyl parathion, Dichlorvos & $\mathrm{N}$-doped and $\mathrm{TiO}_{2} \mathrm{P} 25$ \\
\hline 13. & 2,4-D Diuron, Ametrine & $\mathrm{TiO}_{2}$ slurry \\
\hline 14. & $\begin{array}{l}\text { Alachlor, Atrazine, Chlorfenvinphos, Diuron, Isoproturon, } \\
\text { Pentachlorophenol }\end{array}$ & $\mathrm{TiO}_{2}$ slurry and $\mathrm{Fe}^{2+}$ \\
\hline 15. & Triclopyr, Dantinozid & $\begin{array}{l}\text { Different types of } \mathrm{TiO}_{2} \text { slurries in } \\
\text { tandem with electron acceptors }\end{array}$ \\
\hline 16. & $\begin{array}{l}\text { Cymoxanil, Methomyl, Oxamyl, Dimethoate, Pyrimethanil, } \\
\text { Telone }\end{array}$ & $\mathrm{TiO}_{2}$ slurry and $\mathrm{Fe}^{2+}$ \\
\hline 17. & Dichlorvos, Phorate, Monocrotophos, Parathion & $\mathrm{TiO}_{2} . \mathrm{SiO}_{2}$ Beads \\
\hline
\end{tabular}

\section{Conclusions}

The use of solar derived photocatalysis constitutes a tremendously effective method for the detoxification of water containing pollutants due to its advantage of complete mineralization instead of their transformation into intermediates. Solar driven AOP's were demonstrated as cost-effective emerging methodologies for water decontamination because of their high efficiency, low cost, easy maintenance, and operation, and using a widely available, cheap, and interesting alternative source of energy - the Sun. Further research is necessary to generate the proper application of such technologies in the improvement of the environment.

\section{Funding}

This research received no external funding.

\section{Acknowledgments}

The contribution of Lovely Professional University is greatly acknowledged. 


\section{Conflicts of Interest}

The authors declare no conflict of interest.

\section{References}

1. Abdennouri, M.; Baalala, M.; Galadi, A.; Makhfouk, M.; Bensitel, M.; Nohair, K.; Sadiq, M.; Boussaoud, A.; Barka, N. Photocatalytic degradation of pesticides by titanium dioxide and titanium pillared purified clays. Arab. J. Chem. 2016, 9, S313-S318, https://doi.org/10.1016/j.arabjc.2011.04.005.

2. Khan, S.H.; Pathak; B. ZnO based Photocatalytic Degradation of Persistent Pesticides: A Comprehensive Review. Environ. Nanotechnol. Monit. 2020, 13, https://doi.org/10.1016/j.enmm.2020.100290.

3. Hassan, A.F.; Elhadidy, H.; Abdel-Mohsen, A.M. Adsorption and photocatalytic detoxification of Diazinon using iron and nanotitania modified activated carbons. J Taiwan Inst Chem E 2017, 75, 299-306, https://doi.org/10.1016/j.jtice.2017.03.026.

4. Hossaini, H.; Moussavi, G.; Farrokhi, M. Oxidation of Diazinon in cns-ZnO/LED photocatalytic process: catalyst preparation, photocatalytic examination, and toxicity bioassay of oxidation by-products. Sep. Purif. Technol. 2017, 174, 320-330, https://doi.org/10.1016/j.seppur.2016.11.005.

5. Mahmood, I.; Imadi, S.R.; Shazadi, K.; Gul, A.; Hakeem, K.R. Effects of Pesticides on Environment. In: Plant, Soil and Microbes. Hakeem, K.; Akhtar, M.; Abdullah, S. Eds.; Springer, Cham. 2016; pp. 253-269, https://doi.org/10.1007/978-3-319-27455-3_13.

6. Izadifard, M.; Achari, G.; Langford, C.H. Application of Photocatalysts and LED Light Sources in Drinking Water Treatment. Catalysts 2016, 3, 726-743, https://doi.org/10.3390/catal3030726.

7. Devi, P.I. Pesticides in agriculture-A boon or a curse? A case study of Kerala. Econ. Political Wkly. 2010, 45, 26-27.

8. Rodríguez, S.M. Wastewater treatment by advanced oxidation processes (solar photocatalysis in degradation of industrial contaminants). 2007; pp. 1-40.

9. Hincapie, M.; Maldonado, M.I.; Oller, I.; Gernjak, W.; Sa'nchez-Pe'rez, J.A.; Ballesteros, M.M.; Malato, S. Solar photocatalytic degradation and detoxification of EU priority substances. Catal. Today 2005, 101, 203-210, https://doi.org/10.1016/j.cattod.2005.03.004.

10. Berberidou, C.; Kitsiou, V.; Lambropoulou, D.A.; Antoniadis, A.; Ntonou, E.; Zalidis, G.C.; Poulios., I. Evaluation of an alternative method for wastewater treatment containing pesticides using solar photocatalytic oxidation and constructed wetlands. $J$ Environ Manage 2017, 195, 133-139. https://doi.org/10.1016/j.jenvman.2016.06.010.

11. Tsydenova, O.; Batoev, V.; Batoev, A. Solar-Enhanced Advanced Oxidation Processes for Water Treatment: Simultaneous Removal of Pathogens and Chemical Pollutants. Int J Env Res Pub He 2015, 12, 9542-9561, https://doi.org/10.3390/ijerph120809542.

12. Gogate, P.R.; Pandit, A.B. A review of imperative technologies for wastewater treatment I: Oxidation technologies at ambient conditions. Adv Environ Res 2004, 8, 501-551, https://doi.org/10.1016/S10930191(03)00032-7.

13. Konstantinou, I.K.; Albanis, T.A. Photocatalytic transformation of pesticides in aqueous titanium dioxide suspensions using artificial and solar light. Appl Catal B-Environ 2003, 42, 319-335, https://doi.org/10.1016/S0926-3373(02)00266-7.

14. Pera-Titus, M.; Garcia-Molina, V.; Banos, M.A.; Gime'nez, J.; Esplugas, S. Degradation of chlorophenols by means of advanced oxidation processes. Appl Catal B-Environ 2004, 47, 219-256, https://dx.doi.org/10.1016/j.apcatb.2003.09.010.

15. Lacombe, S.; Keller, N. Photocatalysis: fundamentals and applications in JEP. Environ Sci Pollut R 2012 , 19, 3651-3654. https://doi.org/10.1007/s11356-012-1040-8

16. Beydoun, D.; Amal, R.; Low, G.; McEvoy, S. Role of nanoparticles in photocatalysis. J Nanopart Res 1999 , 1, 439-458, https://doi.org/10.1023/A:1010044830871.

17. Vora J.J.; Chauhan S.K.; Parmar K.C.; Vasava S.B.; Sharma S.; Bhutadiya, L.S. Kinetic study of application of $\mathrm{ZnO}$ as a photocatalyst in heterogeneous medium. E-Jour Chem 2009, 6, 531-536, https://doi.org/10.1155/2009/139753.

18. Hoffmann, M.R. Martin, S.T.; Wonyong, C.; Bahnemann, D.W. Environmental applications of semiconductor photocatalysis. Chemistry Review 1995, 95, 69-96, https://doi.org/10.1021/cr00033a004.

19. Huang, C.P.; Dong, C.; Tang, Z. Advanced chemical oxidation: its present role and potential future in hazardous waste treatment. Waste Management 1993, 13, 361-377, https://doi.org/10.1016/0956053X(93)90070-D.

20. Vag M.C.; Petsas A.S. Advanced Oxidation Processes for the Removal of Pesticides from Wastewater: Recent Review and Trends. 15th International Conference on Environmental Science and Technology Rhodes, Greece, 31 August to 2 September 2017.

21. Orozco, S.; Bandala, E.R.; Arancibia, C.A.; Serrano, B.; Suarez, R.; Hernandez, I. Effect of iron salt on the color removal of water containing the azo-dye reactive blue using photo-assisted $\mathrm{Fe}(\mathrm{II}) / \mathrm{H}_{2} \mathrm{O}_{2}$ and $\mathrm{Fe}$ 
(III) $/ \mathrm{H}_{2} \mathrm{O}_{2} \quad$ systems. $\quad J . \quad$ Photochem. Photobiol. A 2008, $\quad$ 198, 144-149, https://doi.org/10.1016/j.jphotochem.2008.03.001.

22. Erick, R.B.; Raichle, B.W. Solar driven advanced oxidation processes for water decontamination and disinfection. In: Solar Energy Sciences and Engineering Applications. Napoleon Enteria \& Aliakbar Akbarzadeh, CRC Press/Balkema. pp. 95-412.

23. Turchi, C.S.; Ollis, D.F. Photo-catalytic Degradation of organic water contaminants: mechanisms involving hydroxyl radical attack. J. Catal. 1990, 122, 178-192, https://doi.org/10.1016/0021-9517(90)90269-P.

24. Ibhado, A. O.; Fitzpatrick, P. Heterogeneous Photocatalysis: recent advances and applications. Catalysts 2013, 3, 189-218, https://doi.org/10.3390/catal3010189.

25. Lin, Y.; Yuan, G.; Liu, R.; Zhou, S.; Sheehan, S.W.; Wang, D. Semiconductor nanostructure-based photoelectrochemical water splitting: A brief review. Chemical Physics Letters 2011, 507, 209-215, http://doi.org/10.1016/j.cplett.2011.03.074.

26. Fenoll, J.; Ruiz, E.; Hellín, P.; Flores, P.; Navarro, S. Heterogeneous photocatalytic oxidation of cyprodinil and fludioxonil in leaching water under solar irradiation. Chemosphere 2011, 85, 1262-1268, https://doi.org/10.1016/j.chemosphere.2011.07.022.

27. Mills, A.; Le Hunte, S. An overview of semiconductor photocatalysis. J. Photochem. Photobiol. A 1997, 108, 1-35, http://doi.org/10.1016/S1010-6030(97)00118-4.

28. Quiroz, M.A.; Bandala, E.R.; Martínez-huitle. C.A. Advanced Oxidation Processes (AOPs) for Removal of Pesticides from Aqueous Media. Pesticides - Formulations, Effects, Fate. 2007.

29. Sobczyński, D.A. Water purification by photocatalysis on semiconductors. Pol J Environ Stud 2001, 10, 195-205.

30. Liqiang, J.; Yichun, Q.; Baiqi, W.; Shudan, L.; Baojiang, J.; Libin, Y.; Wei, F.; Honggang, F.; Jiazhong, S. Review of photoluminescence performance of nano-sized semiconductor materials and its relationships with photocatalytic activity. Solar Energy Materials and Solar Cells 2006, 90, 1773-1787, https://doi.org/10.1016/j.solmat.2005.11.007.

31. Janotti, A.; Walle, C.G.V. Fundamentals of Zinc Oxide as a Semiconductor. Rep. Prog. Phys 2009, 72.

32. Saber Ahmed, S.; Rasul, M.G.; Brown, R.; Hashib, M.A. Influence of parameters on the heterogeneous photocatalytic degradation of pesticides and phenolic contaminants in wastewater: A short review. J Environ Manage 2011, 92, 311-330, https://doi.org/10.1016/j.jenvman.2010.08.028.

33. Chen, W.; Qi, D.; Gao, X.; ShenWee, A.T. Surface transfer doping of semiconductors. Prog Surf Sci 2009, 84, 279-321, http://doi.org/10.1016/j.progsurf.2009.06.002.

34. Zepp, R.G.; Faust, B.C.; Hoign'e, J. Hydroxyl radical formation in aqueous reactions (pH 3-8) of iron(II) with hydrogen peroxide: The photo- Fenton reaction. Environ. Sci. Technol. 1992, 26, 313-319, https://doi.org/10.1021/es00026a011.

35. Pignatello, J.J.; Oliveros, E.; MacKay, A. Advanced oxidation processes for organic contaminant destruction based on the Fenton reaction and related chemistry. Crit Rev Env Sci Tec 2006, 36, 1-84, https://doi.org/10.1080/10643380500326564.

36. Malato, S.; Blanco, J.; Alarc 'on, D.C.; Maldonado, M.I.; Fern’andez-Ib'ãnez, P.; Gernjak, W. Photocatalytic decontamination and disinfection of water with solar collectors. Catal. Today 2007, 122, 137149, https://doi.org/10.1016/j.cattod.2007.01.034.

37. Silva, M.R.A.; Trov'o, A.G.; Nogueira, R.F.P. Degradation of the herbicide tebuthiuron using solar photoFenton process and ferric citrate complex at circumneutral pH. J Photoch Photobio A 2007, 191, 187-192, https://doi.org/10.1016/j.jphotochem.2007.04.022.

38. Pignatello, J.J. Dark and photoassisted iron (3+)-catalyzed degradation of chlorophenoxy herbicides by hydrogen peroxide. Environ. Sci. Technol. 1992. 26, 944-951, https://doi.org/10.1021/es00029a012.

39. Faust, B.C.; Hoign'e, J. Photolysis of Fe(III)-hydroxy complexes as sources of OH radicals in clouds, fog and rain. Atmos. Environ A 1990, 24, 79-89, https://doi.org/10.1016/0960-1686(90)90443-Q.

40. Lee, C.; Yoon, J. Determination of quantum yields for the photolysis of Fe(III)-hydroxo complexes in aqueous solution using a novel kinetic method. Chemosphere 2004, 57, 1449-1458, https://doi.org/10.1016/j.chemosphere.2004.07.052.

41. Primo, O.; Rivero, M.J.; Ortiz, I. Photo-Fenton process as an efficient alternative to the treatment of landfill leachates. J. Hazard. Mater. 2008, 153, 834-842, https://doi.org/10.1016/j.jhazmat.2007.09.053.

42. Tomašević, A.; Petrović, S.; Mijin, D. Photochemical processes for removal of carbamate pesticides from water. Advan Technol. 2019, 8, 72-81, https://doi.org/10.5937/savteh1902072T.

43. Islam, N.M.; Chatterjee, M.; Ikushima, Y.; Yokoyama, T.; Kawanami, H. Development of a Novel Catalytic Membrane Reactor for Heterogeneous Catalysis in Supercritical CO2. International Journal of Molecular Sciences 2010, 11, 164-172 https://doi.org/10.3390/ijms11010164.

44. Ray, A.K.; Beenackers, M. Development of a new photocatalytic reactor for water purification. Catal. Today 1998, 40, 73-83, https://doi.org/10.1016/S0920-5861(97)00123-5.

45. Franke, R.; Franke, C. Model Reactor for Photocatalytic Degradation of Persistent Chemicals in Ponds and Wastewater. Chemosphere 1999, 39, 2651-2659, https://doi.org/10.1016/S0045-6535(99)00200-3. 
46. Barhon, Z. Photocatalysis-Membrane Separation Coupling Reactor: Removal of Organic Pollutants from Water. Scientific Study \& Research Chemistry \& Chemical Engineering, Biotechnology, Food Industry 2012, 13, 105-108.

47. Malato, S.; Blanco J.; Vidal, A. Applied studies in solar photocatalytic detoxification: an overview. Solar Energy 2003, 75, 329-336, https://doi.org/10.1016/j.solener.2003.07.017.

48. Vela, N.; Pérez-Lucas, G.; Fenoll, J.; Navarro, S. Recent Overview on the Abatement of Pesticide Residues in Water by Photocatalytic Treatment Using $\mathrm{TiO}_{2}$. In: Applications of Titanium dioxide. 2017, http://dx.doi.org/10.5772/intechopen.68802.

49. Navarroa, S.; Fenollb, J.; Velac, N.; Ruizb, E.; Navarro, G. Photocatalytic degradation of eight pesticides in leaching water by use of $\mathrm{ZnO}$ under natural sunlight. J. Hazard. Mater. 2009, 172, 1303-1310, https://doi.org/10.1016/j.jhazmat.2009.07.137.

50. Alalm, G.; Tawfik, A.; Ookawara, S. Combined Solar advanced oxidation and PAC adsorption for removal of pesticides from industrial wastewater. J. Mater. Environ. Sci. 2015, 6, 800-809.

51. Fenoll, J.; Hellín, P.; Martínez, C.M.; Flores, P.; Navarro, S. Semiconductor-sensitized photodegradation of s-triazine and chloroacetanilide herbicides in leaching water using $\mathrm{TiO} 2$ and $\mathrm{ZnO}$ as catalyst under natural sunlight. $J$ Photoch Photobio A: Chem. 2012, 238, 81-87, https://doi.org/10.1016/j.jphotochem.2012.04.017.

52. Moreira, F.C.; Vilar, J.P.; Ana, C.C.; Ferreira, A.C.; dos Santos, F.R.A.; Alpendurada, M.F. Treatment of a pesticide-containing wastewater using combined biological and solar-driven AOPs at pilot scale. Chem Eng J 2012, 209, 429-441, https://doi.org/10.1016/j.cej.2012.08.009.

53. Malato, O.S.; Sa'nchez-Pe'rez, J.A.; Maldonado, M.I.; Gasso, R. Detoxification of wastewater containing five common pesticides by solar AOPs-biological coupled system. Catal. Today 2007, 129, 69-78, https://doi.org/10.1016/j.cattod.2007.06.055.

54. Whangchai1, K.; Sriwichai, T.; Whangchai, N.; Nomura, N. Effect of $\mathrm{TiO}_{2}$ coated substrate photocatalysis on Chlopyrifos insecticide degradation. International Journal of Geomate 2016, 11, 2291-2295, https://doi.org/10.21660/2016.24.1278.

55. Narasaiah, B.P.; Mandal, B.K. Bio-fabricated $\mathrm{CuO}$ NPs as green catalyst towards remediation of environmental pollutants. Letters in Applied NanoBioScience 2019, 8, 597-603, https://doi.org/10.33263/LIANBS83.597603.

56. Habtemariam A.B.; Sibhatu A.K.; Weldegebrieal G.K.; Zelekew O.A.; Tekletsadik B.T. Bio-mediated synthesis of $\mathrm{ZnO}$ nanostructures from Thymus Schimperi leaves extract and its antibacterial and photocatalytic activities. Letters in Applied NanoBioScience 2020, 9, 808-813, https://doi.org/10.33263/LIANBS91.808813.

57. Wang, Z.; Li, C.; Domen, K. Recent developments in heterogeneous photocatalysts for solar-driven overall water splitting. Chem. Soc. Rev. 2019, 48, 2109-2125, https://doi.org/10.1039/C8CS00542G.

58. Wang, Y.; Vogel, A.; Sachs, M.; Sprick, R.S.; Wilbraham, L.; Moniz, S.J.A.; Godin, R.; Zwijnenburg, M.A.; Durrant, J.R.; Cooper, A.I.; Tang, J. Current understanding and challenges of solar-driven hydrogen generation using polymeric photocatalysts. Nature Energy 2019, 4, 746-760, https://doi.org/10.1038/s41560-019-0456-5.

59. Song, L.; Zhu, B.; Jegatheesan, V.; Gray, S.; Duke, M.; Muthukumaran, S. Treatment of secondary effluent by sequential combination of photocatalytic oxidation with ceramic membrane filtration. Environmental Science and Pollution Research 2018, 25, 5191-5202, https://doi.org/10.1007/s11356-017-9070-x.

60. Aliste, M.; Pérez-Lucas, G.; Vela, N.; Garrido, I.; Fenoll, J.; Navarro, S. Solar-driven photocatalytic treatment as sustainable strategy to remove pesticide residues from leaching water. Environmental Science and Pollution Research 2020, 27, 7222-7233, https://doi.org/10.1007/s11356-019-07061-2.

61. Hao,Q.; Liu,Y.; Chen,T.; Guo, Q.; Wei, W.; Ni, B.J. Bi $\mathrm{O}_{3} @$ Carbon Nanocomposites for Solar-Driven Photocatalytic Degradation of Chlorophenols. ACS Applied Nano Materials 2019, 2, 2308-2316, https://doi.org/10.1021/acsanm.9b00206. 